than are the homozygotes ( $A A$ and $a a$ ), but also that this 'overdominance' in heterozygotes' learning ability must exceed some threshold that depends on the selection parameter $s$. The authors give as a numerical example the case where a skilled teaching parent raises $70 \%$ of its $A A$ or aa offspring to be skilled compared with $80 \%$ of the $A a$ offspring; polymorphism is maintained only if the selective margin in favour of skill exceeds $1 / 3$ (that is, $s>1 / 3$; $1+s: 1>4: 3$ ). This is in contrast with conventional population genetics, where heterozygote superiority ensures stable polymorphism.

In the second case, Fieldman and Cavalli-Sforza make a further simpliffcation and assume that all offspring of skilled teaching parents are skilled. There is now completely accurate copying of the teaching parent (skilled or unskilled) by all offspring, irrespective of genotype. Nurture is allimportant; nature is irrelevant. Obviously, the final state is for all the population to be skilled (providing the skill is advantageous, $s>0$ ). Less obviously, there is no unique value for the frequency of the genes $A$ and $a$; rather, there is a neutral equilibrium, with the gene frequency depending on the initial distribution of the skill effects. Even though there are no genetically based selection differences, substantial changes in gene frequency can occur over time if there are initial differences in the distribution of the skill among the genotypes. As an example, the authors assume that the alleles $A$ and $a$ are initially equally common, and that the initial fractions of the genotypes $A A, A a$ and $a a$ that are skilled are $90 \%, 50 \%$ and $10 \%$ respectively: this system will eventually settle to have the frequency of the alleles $A$ and $a$ around $65 \%$ and $35 \%$ respectively, corresponding to a $30 \%$ change in gene frequency. To the unsophisticated observer, it might appear that the 'superior' gene $A$ has asserted itself; in fact, this relatively large gene frequency change is due to a kind of founder effect in a situation where all genotypes are equivalent.

Up to this point, it has been assumed that the probability of acquiring the skill (with consequent selective advantage $s$ ) depends on one 'teaching' parent. The authors next consider the case where both parents affect the outcome. To keep things manageable, the genotype of the offspring is assumed to be irrelevant; the probability that an individual will grow up to be skilled depends only on the phenotype of both parents. In these cases, the gene frequencies of $A$ and $a$ approach some neutral equilibrium, determined by initial values. In contrast, the phenotypic proportions of skilled and

\title{
New shocks in northeastern Alaska
}

from Peter J. Smith

EARTH scientists have often displayed a tendency to interpret a lack of data prematurely in terms of simplicity, presumably through an over-literal application of Occam's Razor. Only a few years ago, for example, it was not uncommon to find the upper mantle being described without qualification as physically homogeneous; and yet as more and more data have accumulated the illusion of homogeneity has receded. This happens to be one of the classic examples of oversimplification through ignorance, but there are many hundreds of others of various degrees of importance, one of which has now been revealed for what it is by Gedney et al. (Geophys. Res. Lett. 4, 175; 1977).

This new case, which concerns the seismicity of northeastern Alaska, is perhaps of minor importance scientifically but warrants attention because of its political overtones. In April 1976 Meyers (NOAA Technical Memorandum EDS NGSDG-1) could find mention of only 10 earthquakes having occurred in Alaska north of $68^{\circ} \mathrm{N}$ throughout the whole of recorded history, thereby apparently confirming the widely held view that northeastern Alaska is relatively aseismic. The fact is, however, that the first seismograph station in Alaska was not constructed until 1935, and from then until 1966 the station closest to the northeastern corner of the state lay several hundred kilometres away near Fairbanks. Moreover, even as recently as 1975 there was no station closer than Fort Yukon on the Arctic Circle. In short, the detection threshold for earthquakes in northeastern Alaska has traditionally been high.

unskilled individuals converge to equilibrium values that depend on $s$ and on the probabilities for given parental combinations to produce skilled offspring. Depending on the relations between these parameters, there may be a unique stable state, or two alternate stable states, or even (in rather extreme circumstances) stable cycles in the proportions of skilled phenotypes.

\section{Disadvantageous 'cultural' traits: the 'kuru model'}

In the models where acquisition of the skill depends on both parents, it is interesting to consider the case where the 'skill' confers a disadvantage $(s<0)$. Such could be the case where an infectious disease or other such disadvan-
But all that changed during 1975 1976 when Gedney and his colleagues installed nine new seismographs in the Brooks Range. This sounds easier than it was, for access to much of this area is by helicopter only. Maintenance during the winter months is therefore impossible; and the recording equipment has been usable for only about half of the time. Nevertheless, during 1976 no fewer than 69 earthquakes in the magnitude range 1-4 were recorded and located (44 of them north of $68^{\circ} \mathrm{N}$ ) and many others were detected but could not be precisely located because of low shock magnitude or equipment failure. In other words, the result of a drastic reduction in the threshold detection limit (from about magnitude 4 to magnitude 1 ) has been to erase the mistaken impression that the northeastern corner of Alaska has a very low seismicity.

This may not be the first time that an area has been shown to be more seismic than previously supposed. The point about northeastern Alaska, however, is that it is the site of the northern section of the oil pipeline and of the Alaskan section of the proposed natural gas pipeline through Canada. The northern part of the oil pipeline has in fact been designed to withstand shocks in excess of magnitude 4. But discoveries such as that by Gedney et al. are bound to strengthen the environmentalists' insistence that any new pipeline projects should be deferred until the data available are adequate to rule out even nastier surprises.

Peter J. Smith is a Reader in Earth Sciences at the Open University.

tageous trait is transmitted from parent to offspring. Feldman and CavalliSforza show that 'a strongly disadvantageous custom can spread through a group provided there is enough pressure on the members of the group to conform to the custom' (page 257). The authors refer to this as "the kuru model', after the degenerative brain disease found among the South Fore linguistic group in the Eastern Highlands of New Guinea, and thought to derive from a slow virus (similar to that producing the rare Creutzfeldt-Jakob disease) transmitted by the custom of eating or sniffing the brain of dead relatives. The authors add that in these cases it would be of considerable interest to introduce the added feature of finite population size in order to 